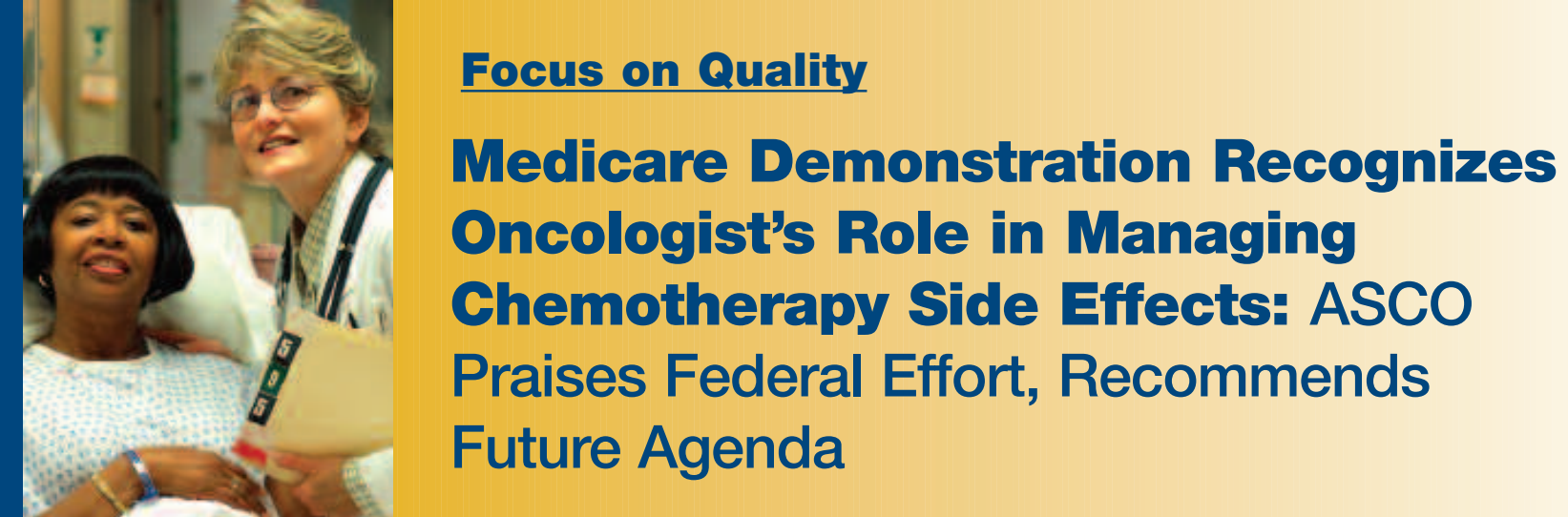

A new Medicare demonstration program to measure and improve quality of care for patients with cancer is an important first step in ensuring that patients always receive the highest quality care, said the President of ASCO. David Johnson, MD, applauded the Centers for Medicare \& Medicaid Services (CMS) for a 1-year demonstration that pays oncologists for measuring the common chemotherapy-related side effects of pain, nausea or vomiting, and fatigue.

"This project recognizes that oncologists play an important role in managing not only cancer but also the complications related to the cancer and its therapies," Dr. Johnson said. "Physicians who take the steps necessary to manage these problems and ensure that patients receive high-quality care should, in our opinion, be properly compensated."

Under the CMS demonstration, physicians ask Medicare patients after each office-based chemotherapy session about their level of pain, nausea/vomiting, and lack of energy, and assign the appropriate billing codes.

Patients' answers to questions about their well-being will provide some information that practitioners may not have obtained otherwise, according to Patricia Ganz, MD, ASCO board member and liaison to the Health Services Committee. "The information could perhaps lead to therapeutic interventions that will improve patient care," Dr. Ganz said.

CMS reported that it will use the data to track improvement in outcomes. Deborah Schrag, MD, chair,
ASCO Health Services Committee, said, "The demonstration will allow the National Cancer Institute and other federal organizations to respond quickly to perceived problems in the delivery of cancer care."

\section{Future Agenda}

More must be done to build on this important effort, all three oncologists said.

"CMS should collaborate [with ASCO and other organizations] to structure ways to make the data collection useful, meaningful, and minimally burdensome," Dr. Schrag recommended. She said ASCO leadership would like to see the demonstration extended to state Medicaid programs.

ASCO leaders believe that collecting additional data would be useful for tracking outcomes in future CMS demonstrations. "It would be helpful," Dr. Ganz said, "to include the type of chemotherapy, reason for chemotherapy, and the stage of the cancer.” Dr. Johnson hopes that in the future, CMS will assess other common side effects of chemotherapy, such as problems associated with immune suppression. The CMS leadership has begun a dialogue with ASCO, to help identify quality measures that the Medicare agency can use as pay-for-performance parameters, he said.

Dr. Ganz hopes that ASCO will have input as CMS develops new initiatives dealing with cancer care. She said, "There may be future opportunities to design and implement research projects on quality of care in physicians' practices that will capitalize on ASCO's ongoing programs." 
The society is working to define quality parameters through projects such as the National Initiative on Cancer Care Quality (NICCQ) and the Quality Oncology Practice Initiative (QOPI). ASCO started NICCQ in 2000 , with a goal of developing a prototype for a national system that could monitor the quality of cancer care.

Begun in 2002, QOPI is an oncologist-led, practice-based, national quality improvement project.

"We've always thought that patients with cancer should have a say in what represents improvement in their care," Dr. Johnson said. He added that the new CMS demonstration gives Medicare patients that say.

It also provides additional payments to oncologists, which, ASCO leadership believes, will avoid interruptions in cancer treatment among millions of Americans ages 65 and older. The Society had predicted problems with access to care as a result of changes in Medicare coverage for chemotherapy drugs, passed in the Medicare Prescription
Drug, Improvement, and Modernization Act of 2003. CMS estimates that it will increase payments for officebased chemotherapy in 2005 by $\$ 300$ million. Physicians receive an additional $\$ 130$ per Medicare patient for each day they provide chemotherapy by intravenous push or infusion if the claim form provides information about the patient's nausea/vomiting, pain, and fatigue.

\section{Get the Facts}

A fact sheet about the Medicare demonstration on quality of care is available at the CMS Web site (www.cms.hhs.gov/media/press/release.asp?Counter= 1245). ASCO's Web site (www.asco.org/ac/1,1003,_12002783,00.asp) also has information on the following:

- Patient Demonstration Form (a questionnaire to give patients to report their side effects from chemotherapy)

- Frequently Asked Questions on Medicare Drug Codes and Demo (pages 7 to 9)

\section{Journal of Oncology Practice ASCO's Newest Resource to Benefit Your Practice}

Each day, you and your staff work to provide patients with the highest quality cancer care. And each day, the quality of your clinical practice affects the delivery of that care.

Journal of Oncology Practice is ASCO's bimonthly publication dedicated to assisting you in making day-to-day decisions about your practice. Whether you're in an office or hospital setting, a community or academic environment, Journal of Oncology Practice will bring you practical information and advice that is immediately applicable to your practice.

Journal of Oncology Practice. Watch for your copy of the next issue.* Make it an indispensable part of your practice.
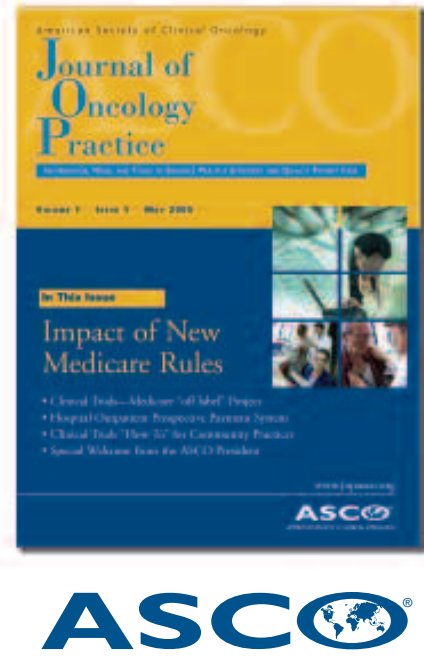

AMERICAN SOCIETY OF CLINICAL ONCOLOGY

*In the initial launch year of 2005, the Journal of Oncology Practice will be mailed to active, active-junior, and associate ASCO members in the United States as a free introductory subscription. Paid subscriptions are also available. For more information or to subscribe, please contact Customer Service at (888) 273-3508 or (703) 519-1430 or jopservice@asco.org. 